\title{
Relationship of Serum Sex-Steroid Hormones and Prostate Volume in African American Men
}

\author{
Michael A. Joseph, ${ }^{1}$ John T. Wei, ${ }^{2}$ Sioban D. Harlow, ${ }^{1}$ Kathleen A. Cooney, ${ }^{2,3}$ \\ Rodney L. Dunn, ${ }^{2}$ Craig A. Jaffe, ${ }^{3}$ James E. Montie, ${ }^{2}$ and David Schottenfeld ${ }^{1,3 *}$ \\ 'Department of Epidemiology, The University of Michigan, Ann Arbor, Michigan \\ ${ }^{2}$ Department of Urology, The University of Michigan, Ann Arbor, Michigan \\ ${ }^{3}$ Department of Internal Medicine, The University of Michigan, Ann Arbor, Michigan
}

\begin{abstract}
BACKGROUND. Previous epidemiologic investigations of the associations of sex-steroid hormones and benign prostatic hyperplasia (BPH) have focused on predominately white populations. The objective of this study was to evaluate potential associations of body mass index (BMI), cigarette smoking, use of alcohol, and endogenous sex-steroid hormones with prostate volume in a population-based sample of African American (AA) men, ages 40-79 yr. METHODS. A total of 369 AA men without clinical evidence of prostate cancer were identified in the Flint Men's Health Study by using a population-based sampling procedure. All subjects underwent a complete urologic evaluation that included prostate volume determination by transrectal ultrasonography and serum assays for androgens and estrogens.

RESULTS. After age adjustment, BMI (weight $(\mathrm{kg}) /$ height $\left.(\mathrm{m})^{2}\right)$ was positively correlated with increasing levels of androstanediol glucuronide (AG), estradiol (E2), estrone sulfate (E1S), and the ratios of E2:total testosterone (TT) and E2:free testosterone (FT); however, increasing BMI was negatively correlated with androstenedione (AD), FT, TT, and sex hormone-binding globulin (SHBG). Multivariable regression models demonstrated that prostate volume increased with age $(P<0.001)$ and BMI $(P=0.02)$ and decreased with increasing levels of SHBG $(P=0.01)$. Larger prostatic volumes were also marginally associated with increasing levels of TT $(P=0.058)$.

CONCLUSION. Circulating serum levels of SHBG and endogenous sex-steroid hormones are correlated with prostate volume and potentially impact the natural history of BPH. However, longitudinal studies are needed to demonstrate the temporal relationships of hormones and growth factors in the pathogenesis of BPH in AA men. Prostate 53: 322-329, 2002.

(c) 2002 Wiley-Liss, Inc.
\end{abstract}

KEY WORDS: sex-steroid hormones; benign prostatic hyperplasia; epidemiology; African-Americans; prostate volume

\section{INTRODUCTION}

Benign prostatic hyperplasia $(\mathrm{BPH})$ is the most common neoplasm in elderly men, afflicting more than $50 \%$ of men by age 60 years and $90 \%$ by age 85 years [1]. $\mathrm{BPH}$ leads to a progressive enlargement of the prostate gland, causing both obstructive and irritative lower urinary tract symptoms (LUTS). The lifetime risk for a 50-year-old man to undergo a prostatectomy for $\mathrm{BPH}$ has been estimated to be as high as $40 \%$ [2] and, in the United States, BPH results annually in more than 380,000 hospitalizations [3]. BPH generates considerable
Grant sponsor: USPHS (NCI); Grant number: P50CA69568; Grant sponsor: USPHS (NIH); Grant number: P50CA69568-05S7.

*Correspondence to: David Schottenfeld, Department of Epidemiology, University of Michigan, School of Public Health, 109 Observatory Street, 2004 SPH I, Ann Arbor, MI 48109-2029.

E-mail: daschott@umich.edu

Received 7 December 2001; Accepted 16 June 2002

DOI $10.1002 /$ pros. 10154 
morbidity and health care costs, and with the aging of the general population, its prevalence is likely to increase.

The causes of BPH have not been fully elucidated, although androgen induction of BPH has been well established [4-6]. The prostate is heavily dependent on androgens for growth and maintenance of its structural and functional integrity. Estrogens, and in particular the elevated plasma free estradiol/free testosterone ratio after age 50 , play a putative role in the pathogenesis of $\mathrm{BPH}$. The increase in serum and intraprostatic estrogen/androgen concentration ratios, as a result of declining testicular function and increasing rate of peripheral aromatization, are associated with stromal hyperplasia [7-10].

Population-based studies that have evaluated the interrelationships of sex-steroid hormones in association with BPH have focused on predominately white populations. The Flint Men's Health Study (FMHS) is investigating the natural history of $\mathrm{BPH}$ and prostate cancer among African American (AA) men. A prior report from the FMHS has shown a positive association between insulin-like growth factor binding protein-3 (IGFBP-3) and prostate volume [11]. Because nonhormonal risk factors such as cigarette smoking, chronic use of alcohol, and BMI may alter serum sex-steroid hormone levels $[9,12]$, this study assesses the nature of the interrelationships of these epidemiologic risk factors and endogenous sex-steroid hormones with prostate volume in a population-based sample of AA men.

\section{MATERIALS AND METHODS}

This analysis is based on data from the FMHS, a study of prostate cancer and BPH among AA men residing in Flint, Michigan. The Institutional Review Board at the University of Michigan Medical School reviewed and approved the study protocol. Details of the study have been described elsewhere [13-15]. Briefly, probability sampling of households or group dwelling units was undertaken in Flint, Michigan, and in select census tracts in Beecher Township. Subjects were stratified by age, representing four 10-year age groups (40-49, 50-59, 60-69, and 70-79 years). Because of the established relationship between age and prostatic morbidity, the pool of eligible subjects aged 60-79 years was oversampled.

Trained interviewers contacted each sampled household in person and conducted a short screening interview to identify and select eligible respondents for the epidemiologic survey. A total of 943 age-eligible AA men were identified for participation in the FMHS in-home interview. The interview included questions on health status, sociodemographic characteristics, tobacco and alcohol consumption, past medical history, and history of LUTS.

After completion of the interview, eligible men were invited to participate in a comprehensive urologic examination. Men were ineligible for the examination if they reported having prostate cancer or having had a prostatectomy. The clinical exam, in general scheduled within 8 weeks of the in-home interview, included a standardized questionnaire of LUTS, height and weight measurements, digital rectal examination (DRE), and determination of urinary flow rate. Participants with an abnormal DRE or elevated total serum prostate specific antigen (PSA) concentration, namely greater than $4.0 \mathrm{ng} / \mathrm{ml}$, were referred for prostate biopsy. Transrectal ultrasonography (B\&K Medical, Denmark; Hitachi Medical Systems, Tarrytown, NY) was also performed on all subjects, and two urologists independently measured the length, width, and height of the prostate. Prostate volume was calculated by using the formula for a prolate ellipsoid $[(\pi / 6) \times$ (width (maximal transverse dimension) $) \times$ (length (maximal anteroposterior dimension) $) \times$ (height (maximal superior-inferior dimension))]. A third reader re-measured the prostate dimensions when differences were recorded of more than $50 \%$ in any dimension between the first two readers. The prostate volume used in this analysis represents the mean calculated volume of the two readers, or if a third reading was performed, the mean of the two closest total volume estimates.

\section{Hormone Analysis}

To minimize the confounding effects of diurnal variations in concentration levels of hormones and growth factors, blood draws were scheduled between 9:00 and 11:00 AM. Sixty-two (16.8\%) of 369 blood draws occurred outside this time window, with 29 occurring before 9:00 AM and 33 after 11:00 AM. The mean concentration levels of dehydroepiandrosterone sulfate (DHEAS), estrone sulfate (E1S), and the ratio of estradiol (E2) to total testosterone (TT), were higher in the men who had blood drawn after 11:00 AM. Exclusion of the 33 men with late blood draws did not alter study results (data not presented); thus, they are included in the analyses presented here. Subjects were asked to refrain from sexual activity for $48 \mathrm{hr}$ and to fast the morning of their scheduled appointment. A total of 50 cc of blood was obtained, from which approximately 36 cc of sera was separated and stored in polystyrene tubes. The tubes were surrounded by a frozen refrigerant pack that was sealed inside a refrigerated cooler and transported by means of overnight delivery to the University of Michigan, Ann Arbor, within $48 \mathrm{hr}$ of the initial blood draw. Serum was immediately labeled and stored in a $-80^{\circ} \mathrm{C}$ freezer. Analyses for 
androstenedione (AD) and free testosterone (FT) were performed at the Chemical Pathology Laboratory at the University of Michigan Hospital. Analyses for DHEAS, TT, E2, E1S, prolactin (PRLN), and sexhormone binding globulin (SHBG) were performed at the Reproductive Sciences Laboratory. The following hormones were measured by commercially available enzyme-linked immunosorbent assays (Diagnostic Systems Laboratory, Inc., Webster, TX), with their respective inter- and intra-assay coefficients of variation, and the number of men for whom results were obtained given in parentheses: androstanediol glucuronide (AG) $(5 \%, 11 \% ; n=353)$, insulin-like growth factor-1 (IGF-1) $(4 \%, 6 \% ; \mathrm{n}=353)$, and IGFBP-3 $(6 \%, 9 \%$; $\mathrm{n}=352) . \mathrm{AD}(11.6 \%, 6 \% ; \mathrm{n}=354)$, DHEAS $(18.14 \%$, $12.53 \% ; \mathrm{n}=366)$, FT $(6.5 \%, 7.3 \% ; \mathrm{n}=354)$, TT $(8.68 \%$, $6.82 \% ; \mathrm{n}=365)$, E2 $(10.21 \%, 6.375 \% ; \mathrm{n}=355), \mathrm{E} 1 \mathrm{~S}$ $(10.27-10.93 \%, 4.11-8.02 \% ; \mathrm{n}=358)$, PRLN (5.83\%, $3.03 \% ; \mathrm{n}=366)$, and SHBG $(18.95 \%, 10.31 \% ; \mathrm{n}=366)$ were quantified by commercially available chemiluminescent immunoassays provided by Bayer Diagnostics (Pittsburgh, PA).

\section{Lifestyle and Anthropometric Risk Factors}

Subjects' smoking history was classified as former smokers (at least 100 cigarettes smoked in a lifetime), current smokers, and never smokers. Current smokers reported the number of cigarettes smoked per day over the past 12 months. The usual number of drinks per week for beer, wine, and hard liquor consumption was assessed for both usual weekday and weekend consumption, with volume sizes specified on the questionnaire. For those men who reported ever consuming alcohol, data were recorded for age when they began to drink each type of beverage, whether they were currently drinking and, if they have stopped, the age at which they discontinued. Subjects were classified as never, former, or current alcohol drinkers, with current drinkers defined as those who reported having at least one drink of beer, wine, or liquor per month for at least the past 6 months. To estimate total alcohol intake in grams (g)/day, servings of specified types of alcoholic beverages were multiplied by $\mathrm{g} /$ serving (liquor $=15.1$, beer $=13.2$, and wine $=10.8 \mathrm{~g} /$ serving) [12]. Body mass index [BMI $=$ weight $(\mathrm{kg}) /$ height $\left.(\mathrm{m})^{2}\right]$ was calculated based on height and weight measurements recorded at the clinical examination and categorized into tertiles of BMI.

\section{Statistical Analyses}

Distributions of demographic, lifestyle, and anthropometric variables were examined by 10-year age groups, and Mantel Haenszel chi-square tests were performed to assess trends across ordered categories.
Spearman correlation coefficients (r) were calculated to evaluate the relationships between age and serum hormone levels. The ratios of E2 to TT and E2 to FT were computed for each 10-year age group. Partial correlation coefficients were calculated to assess the relationship between (1) prostate volume and serum hormones, and (2) BMI and serum hormones while controlling for the possible confounding effects of age. Analysis of variance was performed to assess relationships between lifestyle and anthropometric variables with prostate volume. Multivariable linear regression models were then constructed to assess the association between prostate volume and each hormone, while adjusting for age, BMI, and tobacco and alcohol consumption. As prior analyses of this data set found an association between IGFBP-3 and prostate volume, we also adjusted for this hormone [11]. Forward and backward model-building procedures were used in regression analyses to produce the most parsimonious subset of explanatory factors associated with prostate volume. To adjust for over sampling of the older age groups, age-specific sampling weights were used to calculate overall sample means and to fit multivariable linear regression models. The SURVEYMEANS and SURVEYREG procedures in SAS version 8.2 (SAS Institute, Inc., Cary, NC) were used to obtain the correct variance estimations for overall sample means and estimated beta coefficients. Statistical significance was set at an alpha level of 0.05 .

\section{RESULTS}

A total of 943 age-eligible AA men were identified for participation in the FMHS in-home interview, 819 $(87 \%)$ of whom consented to be interviewed. Of the men interviewed, 87 were ineligible to participate in the clinical phase due to a prior diagnosis of prostate cancer $(n=55)$ or prior surgery $(n=32)$, and 2 were later found to be age-ineligible. Of the remaining 730 men, 11 were excluded from further analyses due to a positive biopsy for cancer, and 350 did not complete the clinical evaluation. Clinical participation rates differed by age category, with older men less likely to participate than younger men; however, nonparticipants did not differ significantly from participants in other demographic or lifestyle characteristics (data not presented). The final study population consisted of 369 men, representing $50.5 \%$ of those eligible to participate in the clinical exam. The designation of clinical and demographic characteristics of the study population has been presented in previous publications [13-15].

Overall, $60.1 \%$ of the men were either married or living with a partner, $74.2 \%$ reported that they had completed a high school education or equivalent, and nearly $65 \%$ reported an annual income of less than 
$\$ 50,000$ (Table I). With respect to smoking status and use of alcohol, $44.5 \%$ of the men were current smokers and $53.2 \%$ currently consumed alcohol, but the prevalence of smoking and drinking decreased with age. Among current smokers, $47.4 \%$ reported having smoked 20 cigarettes or more per day over the past year. The median BMI was $27.7 \mathrm{~kg} / \mathrm{m}^{2}$ (interquartile range, $23.8-31.3 \mathrm{~kg} / \mathrm{m}^{2}$ ), and approximately one third of the study population was classified as being obese $\left(B M I \geq 30 \mathrm{~kg} / \mathrm{m}^{2}\right)$ [16]. The distribution of BMI did not vary by age.

The median and interquartile ranges for the panel of hormones investigated were as follows: AG (6.4, 4.6$8.8 \mathrm{ng} / \mathrm{ml}), \mathrm{AD}(1.1,0.8-1.3 \mathrm{ng} / \mathrm{ml})$, DHEAS (140.9, 84.5-202.7 mg/dl), FT (13.1, 9.5-17.4 pg/ml), TT
(582.4, 423.9-757.1 ng/ml), E2 $(29.5,23.4-36.9 \mathrm{pg} / \mathrm{ml})$, E1S $(1.9,1.3-3.0 \mathrm{pg} / \mathrm{ml})$, PRLN $(7.1,5.4-10.1 \mathrm{ng} / \mathrm{ml})$, and SHBG $(29.6,21.3-43.1 \mathrm{nmol} / \mathrm{l})$.

There were substantial correlations between TT and SHBG $(r=0.60)$ and TT and FT $(r=0.58)$, and weaker correlations between TT and AD $(r=0.38)$ and TT and E2 $(r=0.27)$ (Table II). E1S was negatively correlated with TT $(r=-0.19)$ and SHBG $(r=-0.34)$. Both E2 and E1S were positively correlated with AD, DHEAS, and FT. SHBG was negatively correlated with DHEAS $(r=-0.15)$ and E1S $(r=-0.34)$. Serum levels of AG were not correlated with the levels of other hormones.

Overall, the median prostate volume was $24.9 \mathrm{~g}$ (interquartile range $=19.4-31.6 \mathrm{~g}$ ). There was a significant correlation between age and prostate volume

TABLE I. Demographic and Lifestyle Characteristics of Study Population by Age

\begin{tabular}{|c|c|c|c|c|c|c|}
\hline \multirow[b]{2}{*}{ Characteristic } & \multirow[b]{2}{*}{$\begin{array}{l}\text { Total } \\
\text { N (\%) }\end{array}$} & \multicolumn{4}{|c|}{ Age (yr) } & \multirow[b]{2}{*}{$P$ value } \\
\hline & & $\begin{array}{l}40-49 \\
\mathrm{~N}(\%)\end{array}$ & $\begin{array}{l}50-59 \\
\mathrm{~N}(\%)\end{array}$ & $\begin{array}{l}60-69 \\
N(\%)\end{array}$ & $\begin{array}{l}70-79 \\
\mathrm{~N}(\%)\end{array}$ & \\
\hline Marital status & & & & & & 0.016 \\
\hline Married/living with partner & $218(60.1)$ & $70(64.8)$ & $62(53.5)$ & $56(60.9)$ & $30(57.7)$ & \\
\hline Divorced/separated/widowed & $121(30.7)$ & $24(22.2)$ & $48(41.4)$ & $28(30.4)$ & $21(40.4)$ & \\
\hline Never married & $29(9.1)$ & $14(13.0)$ & $6(5.2)$ & $8(8.7)$ & $1(1.9)$ & \\
\hline Completed high school & $256(74.2)$ & $90(83.3)$ & $88(75.9)$ & $54(58.1)$ & $24(46.2)$ & $0.0001^{\mathrm{a}}$ \\
\hline Income & & & & & & $0.0001^{\mathrm{a}}$ \\
\hline$<\$ 15,000$ & $104(26.7)$ & $24(23.1)$ & $31(27.9)$ & $26(28.3)$ & $23(45.1)$ & \\
\hline$\$ 15,000-\$ 29,999$ & $83(20.1)$ & $12(11.5)$ & $26(23.4)$ & $28(30.4)$ & $17(33.3)$ & \\
\hline$\$ 30,000-\$ 49,999$ & $62(17.4)$ & 19 (18.3) & 13 (11.7) & $23(25.0)$ & $7(13.7)$ & \\
\hline$\geq \$ 50,000$ & $109(35.8)$ & $49(47.1)$ & $41(36.9)$ & $15(16.3)$ & $4(7.8)$ & \\
\hline Smoking status & & & & & & 0.0001 \\
\hline Current smoker & $150(44.5)$ & $58(53.7)$ & $53(45.7)$ & $24(25.8)$ & $15(28.9)$ & \\
\hline Former smoker & $139(33.4)$ & $27(25.0)$ & $36(31.0)$ & $47(50.5)$ & $29(55.8)$ & \\
\hline Never smoker & $80(22.1)$ & $23(21.3)$ & $27(23.3)$ & $22(23.7)$ & $8(15.4)$ & \\
\hline Cigarettes smoked per day ${ }^{b}$ & & & & & & $0.025^{\mathrm{a}}$ \\
\hline $1-9$ & $34(20.0)$ & $10(17.2)$ & $12(22.6)$ & $4(16.7)$ & $8(53.3)$ & \\
\hline $10-19$ & $49(32.5)$ & $17(29.3)$ & $21(39.6)$ & $7(29.2)$ & $4(26.7)$ & \\
\hline$\geq 20$ & $67(47.4)$ & $31(53.5)$ & $20(37.7)$ & $13(54.2)$ & $3(20.0)$ & \\
\hline Alcohol drinking status & & & & & & 0.049 \\
\hline Current drinker & $183(53.2)$ & $68(63.0)$ & $56(48.3)$ & $40(43.0)$ & $19(37.3)$ & \\
\hline Former drinker & $129(32.4)$ & $27(25.0)$ & $42(36.2)$ & $37(39.8)$ & $23(45.1)$ & \\
\hline Never drinker & $56(14.4)$ & $13(12.0)$ & $18(15.5)$ & $16(17.2)$ & $9(17.7)$ & \\
\hline Alcohol intake $(\mathrm{g} / \mathrm{day})^{\mathrm{c}}$ & & & & & & $0.016^{\mathrm{a}}$ \\
\hline$\leq 25.27$ & $63(31.9)$ & $14(20.6)$ & $24(42.9)$ & $20(50.0)$ & $5(26.3)$ & \\
\hline $25.28-65.31$ & $60(32.5)$ & $23(33.8)$ & $17(30.4)$ & $12(30.0)$ & $8(42.1)$ & \\
\hline$\geq 65.32$ & $60(35.6)$ & $31(45.6)$ & $15(26.8)$ & $8(20.0)$ & $6(31.6)$ & \\
\hline Body mass index $\left(\mathrm{kg} / \mathrm{m}^{2}\right)$ & & & & & & $0.108^{a}$ \\
\hline$<25$ & $119(31.4)$ & $30(27.8)$ & $41(35.3)$ & $30(32.3)$ & $18(34.6)$ & \\
\hline $25-29.9$ & $134(35.2)$ & $36(33.3)$ & $41(35.3)$ & $35(37.6)$ & $22(42.3)$ & \\
\hline$\geq 30$ & $116(33.4)$ & $42(38.9)$ & $34(29.3)$ & $28(30.1)$ & $12(23.1)$ & \\
\hline
\end{tabular}

${ }^{a}$ Mantel-Haenszel chi-square test for trend, otherwise chi-square test for association.

${ }^{b}$ Percentages obtained from total number of current smokers within each age category.

'Percentages obtained from total number of current drinkers within each age category. 
TABLE II. Spearman Correlation Coefficients Between the Measured Hormones*

\begin{tabular}{|c|c|c|c|c|c|c|c|c|c|c|}
\hline & $\mathrm{AG}$ & $\mathrm{AD}$ & DHEAS & FT & $\mathrm{TT}$ & E2 & E1S & E2:TT & E2:FT & PRLN \\
\hline $\mathrm{AD}$ & 0.04 & - & - & - & - & - & - & - & - & - \\
\hline DHEAS & 0.10 & $0.34^{\mathrm{a}}$ & - & - & - & - & - & - & - & - \\
\hline FT & -0.01 & $0.58^{\mathrm{a}}$ & $0.33^{\mathrm{a}}$ & - & - & - & - & - & - & - \\
\hline $\mathrm{TT}$ & 0.01 & $0.38^{\mathrm{a}}$ & 0.05 & $0.58^{a}$ & - & - & - & - & - & - \\
\hline E2 & 0.07 & $0.32^{\mathrm{a}}$ & $0.21^{\mathrm{a}}$ & $0.32^{\mathrm{a}}$ & $0.27^{\mathrm{a}}$ & - & - & - & - & - \\
\hline E1S & 0.04 & $0.23^{a}$ & $0.59^{a}$ & $0.23^{a}$ & $-0.19^{a}$ & $0.38^{\mathrm{a}}$ & - & - & - & - \\
\hline E2:TT & 0.06 & $-0.12^{\mathrm{a}}$ & 0.05 & $-0.28^{a}$ & $-0.67^{\mathrm{a}}$ & $0.45^{\mathrm{a}}$ & $0.43^{\mathrm{a}}$ & - & - & - \\
\hline E2:FT & 0.08 & $-0.28^{\mathrm{a}}$ & $-0.18^{\mathrm{a}}$ & $-0.64^{\mathrm{a}}$ & $-0.32^{\mathrm{a}}$ & $0.44^{\mathrm{a}}$ & 0.10 & $0.65^{\mathrm{a}}$ & - & - \\
\hline PRLN & 0.02 & $0.22^{\mathrm{a}}$ & 0.08 & $0.14^{\mathrm{a}}$ & 0.09 & 0.09 & 0.09 & -0.04 & -0.07 & - \\
\hline SHBG & 0.02 & $0.14^{\mathrm{a}}$ & $-0.15^{\mathrm{a}}$ & 0.08 & $0.60^{\mathrm{a}}$ & $0.11^{\mathrm{a}}$ & $-0.34^{\mathrm{a}}$ & $-0.45^{\mathrm{a}}$ & 0.01 & 0.10 \\
\hline
\end{tabular}

*AG, androstanediol glucuronide (ng/ml); AD, androstenedione (ng/ml); DHEAS, dehydroepiandrosterone sulfate (mg/dl); FT, free testosterone (pg/ml); TT, total testosterone ( $\mathrm{ng} / \mathrm{ml}) ; \mathrm{E} 2$, estradiol (pg/ml); E1S, estrone sulfate (pg/ml); E2:TT, estradiol:total testosterone ratio; E2:FT, estradiol:free testosterone ratio; SHBG, sex hormone-binding globulin (nmol/l); PRLN, prolactin (ng/ml). ${ }^{\text {a }} P<0.05$

$(\mathrm{r}=0.32 ; P<0.001)$ (Fig. 1), with prostate volumes of $50 \mathrm{~g}$ or greater occurring exclusively in men ages $55 \mathrm{yr}$ and older.

Significant age-related decreases in the levels of several hormones were observed, including $\mathrm{AD}(\mathrm{r}=-0.19$; $P<0.001)$, DHEAS $(\mathrm{r}=-0.35 ; P<0.001)$, FT $(\mathrm{r}=-0.26$; $P<0.001)$, E2 $(\mathrm{r}=-0.11 ; P=0.044)$, E1S $(\mathrm{r}=-0.20 ; P<$ 0.001), and PRLN ( $\mathrm{r}=-0.13 ; P=0.015)$ (Table III). TT levels also tended to decrease with age, although this relationship was of marginal significance $(r=-0.10$; $P=0.062)$. Levels of SHBG $(r=0.17 ; P<0.001)$ and the ratio of E2 to FT $(r=0.13 ; P=0.018)$ increased with age. After age adjustment, prostate volume correlated positively with AG $(\mathrm{r}=0.12 ; P=0.028)$, E1S $(\mathrm{r}=0.13$;

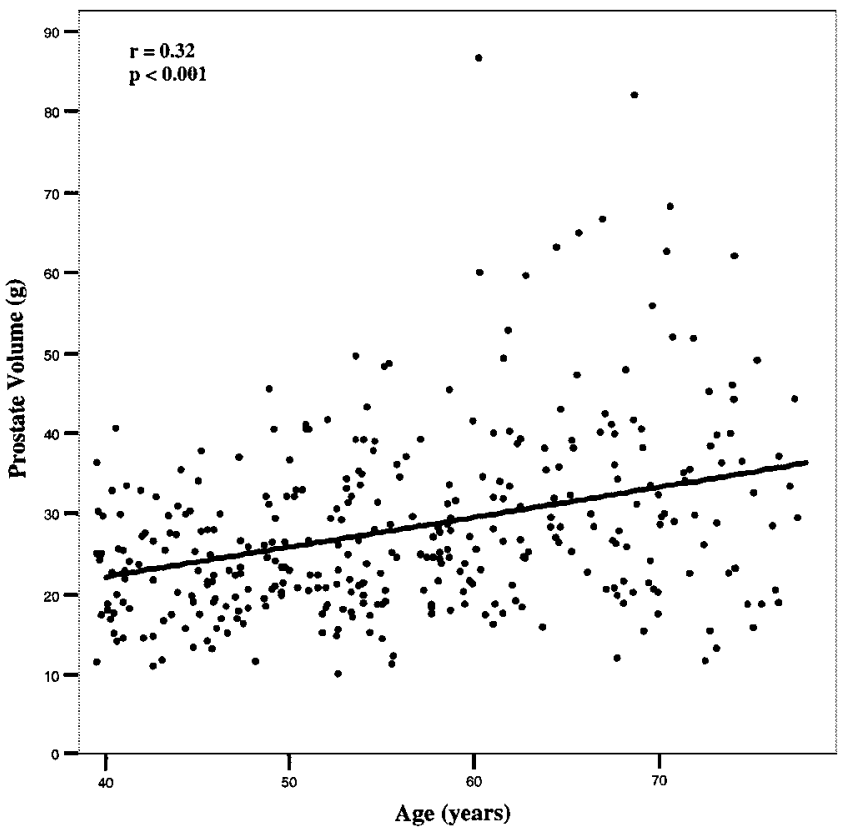

Fig. I. Correlation between measured prostate volume and age.
$P=0.018)$, and the ratio of E2 to TT $(\mathrm{r}=0.12 ; P=0.033)$, and negatively with SHBG $(\mathrm{r}=-0.17 ; P=0.002)$.

Associations of obesity with altered endogenous sex hormone levels were also observed. Increasing levels of BMI were strongly associated with decreases in AD, FT, $\mathrm{TT}$, and SHBG. Increasing BMI was positively correlated with AG, E2, E1S, and an increasing E2:TT ratio and E2:FT ratio.

Statistically significant differences in the mean prostate volume were associated with smoking status, alcohol drinking status, and BMI (Table IV). Current and former drinkers had smaller prostates than never drinkers, although no dose-response relationship was observed. Higher tertile levels of BMI were also associated with larger mean prostate volumes, with average prostate gland volumes increasing with increasing BMI tertile, from 24.63 to $28.34 \mathrm{~g}$.

Results from the multivariable linear regression models indicated that prostatic volume decreased with increasing levels of SHBG $(P=0.011)$ (Table V). Increasing levels of TT $(P=0.058)$ were marginally associated with increasing prostate volume. Increasing age $(P<0.001)$ was associated with increases in prostate volume, even after controlling for BMI, IGFBP-3, TT, and SHBG. Additionally, increasing levels of BMI were significantly associated with larger prostate volumes $(P=0.021)$. In multivariable models constructed with indicator variables to represent the tertile categories of BMI, a statistically significant difference was not found when comparing the prostate volumes of overweight men (BMI between 25 and $29.9 \mathrm{~kg} / \mathrm{m}^{2}$ ) to men with a BMI of less than $25 \mathrm{~kg} / \mathrm{m}^{2}$ (data not presented). In contrast, obese men (BMI $\geq 30 \mathrm{~kg} / \mathrm{m}^{2}$ ) had significantly higher prostate volumes compared with men with a BMI of less than $25 \mathrm{~kg} / \mathrm{m}^{2}$. Each unit $\left(\mathrm{kg} / \mathrm{m}^{2}\right)$ increase in BMI among men with a BMI $\geq 30 \mathrm{~kg} / \mathrm{m}^{2}$ was a predictor of higher prostate volume $(3.74 \mathrm{~g})$. No 
TABLE III. Spearman Correlations of Hormones With Age, BMI, and Prostate Volume*

\begin{tabular}{lccccccccccc}
\hline & AG & AD & DHEAS & FT & TT & E2 & E1S & E2:TT & E2:FT & PRLN & SHBG \\
\hline Age $(\mathrm{yr})^{2}$ & -0.06 & $-0.19^{\mathrm{a}}$ & $-0.35^{\mathrm{a}}$ & $-0.26^{\mathrm{a}}$ & -0.10 & $-0.11^{\mathrm{b}}$ & $-0.20^{\mathrm{a}}$ & 0.02 & $0.13^{\mathrm{b}}$ & $-0.13^{\mathrm{b}}$ & $0.17^{\mathrm{a}}$ \\
BMI $^{\mathrm{c}}\left(\mathrm{kg} / \mathrm{m}^{2}\right)$ & $0.12^{\mathrm{b}}$ & $-0.14^{\mathrm{b}}$ & 0.03 & $-0.21^{\mathrm{a}}$ & $-0.39^{\mathrm{a}}$ & $0.15^{\mathrm{d}}$ & $0.20^{\mathrm{a}}$ & $0.47^{\mathrm{a}}$ & $0.31^{\mathrm{a}}$ & 0.04 & $-0.28^{\mathrm{a}}$ \\
Prostate volume $^{\mathrm{c}}(\mathrm{g})$ & $0.12^{\mathrm{b}}$ & 0.04 & 0.08 & 0.02 & -0.07 & 0.09 & $0.13^{\mathrm{b}}$ & $0.12^{\mathrm{b}}$ & 0.04 & -0.08 & $-0.17^{\mathrm{d}}$ \\
\hline
\end{tabular}

*BMI, body mass index; other abbreviations as in Table II.

${ }^{\mathrm{a}} P<0.001$.

${ }^{\mathrm{b}} P<0.05$.

${ }^{\mathrm{c}}$ Age adjusted.

${ }^{\mathrm{d}} P<0.01$.

statistically significant relationship of either tobacco or alcohol consumption with prostate volume was observed.

\section{DISCUSSION}

In a population-based study, we assessed the nature of the interrelationships of epidemiologic risk factors and endogenous sex-steroid hormones with prostate volume in AA men. Most of the available literature describing endocrine associations in $\mathrm{BPH}$ was based on Caucasian populations. After adjustment for age and IGFBP-3, increases in prostate volume were independently associated with decreases in the levels of SHBG.

TABLE IV. Mean Prostate Volume (g) and Standard Errors (SE) for Selected Potential Confounding Factors

\begin{tabular}{lcc}
\hline & $\begin{array}{c}\text { Mean prostate } \\
\text { volume (SE) }\end{array}$ & $P$ value ${ }^{\mathrm{a}}$ \\
\hline Smoking status & & 0.01 \\
$\quad$ Current & $24.88(0.72)$ & \\
$\quad$ Former & $28.19(0.96)$ & \\
$\quad$ Never & $28.08(1.30)$ & \\
Cigarettes smoked per day & & 0.528 \\
$\quad 1-9$ & $23.00(1.57)$ & \\
$\quad 10-19$ & $25.45(1.35)$ & \\
$\geq 20$ & $25.25(0.98)$ & \\
Alcohol drinking status & & \\
$\quad$ Current & $25.41(0.73)$ & \\
$\quad$ Former & $27.12(0.83)$ & \\
$\quad$ Never & $30.23(1.74)$ & \\
Alcohol intake (g/day) & & 0.705 \\
$\quad 1-25.06$ & $26.14(1.45)$ & \\
$25.07-65.31$ & $25.91(1.14)$ & \\
$\quad \geq 65.32$ & $24.40(1.19)$ & \\
Body mass index (kg/m $\left.{ }^{2}\right)$ & & \\
$\quad<25$ & $24.63(0.80)$ & \\
$25-29.9$ & $26.97(0.92)$ & \\
$\geq 30$ & $28.34(1.03)$ & \\
\hline a $P$ value in analysis of variance. & & \\
& &
\end{tabular}

Increases in prostate volume were marginally associated with increases in the serum levels of TT.

Steroid hormones, in particular androgens and estrogens, are thought to play major roles in the development of $\mathrm{BPH}$, but the precise mechanisms by which each contributes to this process remain unclear. Testosterone and its potent intraprostatic metabolite dihydrotestosterone (DHT) stimulate prostatic growth and are responsible for the maintenance of secondary sex characteristics. However, as noted by Lagiou and colleagues [17], the epidemiologic evidence implicating testosterone in the pathogenesis of $\mathrm{BPH}$ was conflicting. Potential reasons for discrepancies may be attributed to observations limited to hospitalized patients and inappropriate comparison groups, inadequate control of confounding risk factors, or lack of standardization in diurnal blood sampling and assay methodology [5]. Although our results on the association of TT with prostate volume failed to reach statistical significance in bivariate analyses, the marginal significance of findings in multivariable analyses suggested that the cumulative lifetime level of TT, in conjunction with decreased levels of SHBG, were predictive of risk of BPH.

It has been demonstrated that DHT is the more potent androgen metabolite, and after binding to the

TABLE V. Multiple Linear Regression-Derived Beta Coefficients and $P$ Values for Factors Significantly Associated With Prostate Volume*

\begin{tabular}{lcc}
\hline Factor & Beta coefficient $^{\mathrm{a}}(\mathrm{SE})$ & $P$ value \\
\hline Age $(\mathrm{yr})$ & $0.01445(0.00205)$ & $<0.001$ \\
BMI $\left(\mathrm{kg} / \mathrm{m}^{2}\right)$ & $0.00856(0.00369)$ & 0.021 \\
SHBG $(\mathrm{nmol} / \mathrm{l})$ & $-0.00282(0.00110)$ & 0.011 \\
TT $(\mathrm{ng} / \mathrm{ml})$ & $0.00016(0.00008)$ & 0.058 \\
\hline
\end{tabular}

*Natural log transformation of prostate volume used in regression analyses. BMI, body mass index; SHBG, sex-hormone binding globulin; TT, total testosterone.

${ }^{\mathrm{a}}$ Model R-square $=0.1752$; adjusted for insulin-like growth factor binding protein-3. 
androgen receptor (AR), the DHT-AR complex stimulates the transcription of a cascade of androgenresponsive genes. AG is a major metabolite of DHT and is considered to be a useful marker of DHT activity [18]. However, circulating levels of AG did not appear to be significantly related to prostate volume in our population of AA men but may not accurately reflect intraprostatic DHT and androstanediol concentration levels [6,19].

The aging prostate is subjected to the hormonal effects of stromal and epithelial interactions and of the relatively increasing ratio of estrogens to androgens. Although our initial analyses indicated significant correlations of age-adjusted prostate volume with E1S and the ratio of E2 to TT, multivariable analyses suggested that prostate volume was not explained sufficiently by ratios of either E2 to TT or E2 to FT.

In a prior publication, we reported evidence of an apparent association of serum IGFBP-3 with prostate enlargement but no association with IGF-1 [11]. Prior studies investigating peptide growth factors such as IGF-1 and its major binding protein IGFBP-3 have underscored the important role of the IGF system in prostatic neoplasia $[20,21]$. Prostate cancer risk has been associated with increased serum IGF-1 levels and inversely with serum IGFBP-3 levels [22,23]. Two epidemiologic studies have not demonstrated any relationship between serum IGF-1 levels and prostate volume [20] or histologically confirmed BPH [24]. Our data suggested that increasing levels of IGFBP-3 were inversely correlated with TT and positively associated with an elevated E2:TT ratio. Increasing BMI was also correlated positively with increasing levels of IGFBP-3. We may hypothesize, therefore, that the apparent association of IGFBP-3 with increased prostatic volume was indicative of a more direct causal mechanism involving the interaction of the sex-steroid hormones.

The associations between prostate volume and endocrine factors observed in this study were not fully explained by confounding due to age, tobacco or alcohol consumption, or obesity, although age and BMI served as independent risk factors for prostatic enlargement. Higher levels of BMI, particularly in excess of $30 \mathrm{~kg} / \mathrm{m}^{2}$ were predictive of increased prostate volumes in the AA men. Approximately $33 \%$ of our study population was classified as being obese $\left(B M I \geq 30 \mathrm{~kg} / \mathrm{m}^{2}\right)$. As noted in two other studies $[25,26]$, increased BMI was associated with larger prostate volumes. In FMHS AA men, levels of E1S and E2 increased with increasing BMI, whereas serum levels of both FT and TT declined.

Alcohol consumption and tobacco use are potential risk factors for $\mathrm{BPH}$ and have been postulated to alter levels of serum sex-steroid hormones. As noted by several authors $[9,12,27]$, most previous epidemiologic studies of risk factors for BPH have shown an inverse association of $\mathrm{BPH}$ with use of alcohol and cigarette smoking. We observed in FMHS participants that current and former alcohol drinkers had smaller prostates than never drinkers, while current smokers had smaller prostates than never smokers. However, the observed associations of cigarette smoking and alcohol drinking with prostate volume disappeared in multivariable analyses.

This study has some limitations. The cross-sectional nature of this study design did not permit evaluation of temporal trends based on repeated observations in subjects. Longitudinal studies of the associations between endogenous sex steroids, IGF-1, IGFBP-3, and prostate volume are needed to assess accurately the impact of these factors on the aging prostate [11]. There was the potential for selection bias, as only half the eligible subjects completed the clinical phase of the FMHS protocol. An evaluation of potential selection bias in the FMHS observed that the participants tended to be younger and experienced more urologic symptoms when compared with nonparticipants [13]. Selection bias would have occurred if nonparticipants differed from participants in the distribution of risk factors and hormonal profiles in relation to prostate volumes, which could not be evaluated. Finally, our most parsimonious multivariable model explained only $17.5 \%$ of the variance in prostate volume, suggesting that unmeasured growth factors or interactive lifestyle (e.g., dietary) and genetic risk factors play potentially a facilitating role in the induction and maintenance of $\mathrm{BPH}$ in AA men.

In summary, the present study observed that serum levels of SHBG and possibly TT were associated with increased prostatic volume. Prostatic enlargement in AA men may involve complex interrelationships of sex-steroid hormones, increasing age, and BMI. Future longitudinal studies are needed to fully describe the temporal relationships of endogenous sex-steroid hormones, IGF-1, IGFBP-3, and potential interactions with epidemiologic and genetic risk factors in the natural history of increasing prostatic volume associated with $\mathrm{BPH}$ and lower urinary tract symptom morbidity.

\section{CONCLUSIONS}

The natural history of $\mathrm{BPH}$ reflects both pathologic and clinical sequelae of cumulative exposures to a complex of sex-steroid hormones, growth factors, and binding proteins. The FMHS of AA men underscores the importance of age and body composition in relationship to the levels in blood and, presumably, in prostatic tissue of the hormonal determinants of prostate volume. 


\section{ACKNOWLEDGMENTS}

The authors thank Kay M. Doerr and Mark J. Velarde for their efforts in scheduling the clinical examinations, and Drs. Barry G. England and Donald A. Giacherio for their technical assistance in performing the hormone assays. We also thank the study participants, for without their involvement, the Flint Men's Health Study would not be possible. This project was funded by a ORMH Training Grant for Minority Health Professionals.

\section{REFERENCES}

1. McConnell JD. Epidemiology, etiology, pathophysiology, and diagnosis of benign prostatic hyperplasia. In: Walsh PC, Retik AB, Vaughan ED, Wein AJ, editors. Campbell's urology. 7th ed. Philadelphia: WB Saunders; 1998. p 14291452.

2. Oesterling JE. Benign prostatic hyperplasia: a review of its histogenesis and natural history. Prostate 1996;S6:67-73.

3. NCHS, CDC, DHHS. Detailed diagnoses and procedures, National Hospital Discharge Survey, 1997. Vital and health statistics. Series 13, No. 145. Atlanta, GA: NCHS, CDC, DHHS; December 1999.

4. Griffiths K, Eaton CL, Harper ME, Peeling B, Davies P. Steroid hormones and the pathogenesis of benign prostatic hyperplasia. Eur Urol 1991;20 ( Suppl 2):68-77.

5. Partin AW, Oesterling JE, Epstein JI, Horton R, Walsh PC. Influence of age and endocrine factors on the volume of benign prostatic hyperplasia. J Urol 1991;145:405-409.

6. Montie JE, Pienta KJ. Review of the role of androgenic hormones in the epidemiology of benign prostatic hyperplasia and prostate cancer. Urology 1994;43:892-899.

7. Griffiths K. Molecular control of prostate growth. In: Kirby R, Mc Connell J, Fitzpatrick J, Roehrborn C, Boyle P, editors. Textbook of benign prostatic hyperplasia. Oxford, UK: ISIS Medical Media; 1996. p 23-55.

8. Krieg M, Nass R, Tunn S. Effect of aging on endogenous level of 5 alpha-dihydrotestosterone, testosterone, estradiol, and estrone in epithelium and stroma of normal and hyperplastic human prostate. J Clin Endocrinol Metab 1993;77:375381.

9. Gann PH, Hennekens CH, Longcope C, Verhoek-Oftedahl W, Grodstein F, Stampfer MJ. A prospective study of plasma hormone levels, nonhormonal factors, and development of benign prostatic hyperplasia. Prostate 1995;26:40-49.

10. Suzuki K, Ito K, Ichinose $Y$, Kurokawa K, Suzuki T, Imai K, Yamanaka H, Honma S. Endocrine environment of benign prostatic hyperplasia: prostate size and volume are correlated with serum estrogen concentration. Scand J Urol Nephrol 1995; 29:65-68

11. Sarma AV, Jaffe CA, Schottenfeld D, Dunn RL, Montie JE, Cooney KA, Wei JT. Insulin-like growth factor-1, insulin-like growth factor binding protein- 3 and body mass index: clinical correlates of prostate volume among African-American men. Urology 2002;59:362-367.

12. Platz EA, Rimm EB, Kawachi I, Colditz GA, Stampfer MJ, Willett WC, Giovannucci E. Alcohol consumption, cigarette smoking, and risk of benign prostatic hyperplasia. Am J Epidemiol 1999;149:106-115.

13. Heeringa SG, Alcser KH, Doerr K, Strawderman M, Cooney K, Medbery B, Schottenfeld D. Potential selection bias in a community-based study of PSA levels in African-American men. J Clin Epidemiol 2001;54:142-148.

14. Cooney KA, Strawderman MS, Wojno KJ, Doerr KM, Taylor A, Alcser KH, Heeringa SG, Taylor JMG, Wei JT, Montie JE, Schottenfeld D. Age-specific distribution of serum prostatespecific antigen in a community-based study of AfricanAmerican men. Urology 2001;57:91-96.

15. Wei JT, Schottenfeld D, Cooper K, Taylor JM, Faerber GJ, Velarde MA, Bree R, Montie JE, Cooney K. The natural history of lower urinary tract symptoms in black American men: relationships with aging, prostate size, flow rate and bothersomeness. J Urol 2001;165:1521-1525.

16. WHO Expert Committee. Physical status: the use and interpretation of anthropometry. WHO Technical Report Series no. 854. Geneva: WHO; 1995.

17. Lagiou P, Mantzoros CS, Tzonou A, Signorello LB, Lipworth L, Trichopoulos D. Serum steroids in relation to benign prostatic hyperplasia. Oncology 1997;54:497-501.

18. Ross RK, Bernstein L, Lobo RA, Shimizu H, Stanczyk FZ, Pike MC, Henderson BE. 5-alpha-reductase activity and risk of prostate cancer among Japanese and US white and black males. Lancet 1992;339:887-889.

19. Monti S, Di Silverio F, Lanzara S, Varasano P, Martini C, Tosti-Croce C, Sciarra F. Insulin-like growth factor-I and -II in human benign prostatic hyperplasia: relationship with binding proteins 2 and 3 and androgens. Steroids 1998;63:362-366.

20. Harman SM, Metter EJ, Blackman MR, Landis PK, Carter HB. Serum levels of insulin-like growth factor I (IGF-I), IGF-II, IGFbinding protein-3, and prostate-specific antigen as predictors of clinical prostate cancer. J Clin Endocrinol Metab 2000;85:42584265.

21. Cohen P. Serum insulin-like growth factor-I levels and prostate cancer risk: interpreting the evidence. J Natl Cancer Inst 1998; 90:876-879.

22. Cohen P, Clemmons DR, Rosenfeld RG. Does the GH-IGF axis play a role in cancer pathogenesis? Growth Horm IGF Res 2000; 10:297-305.

23. Finne $P$, Auvinen A, Koistinen H, Zhang W-M, Määttänen L, Rannikko S, Tammela T, Seppälä M, Hakama M, Stenman U-H. Insulin-like growth factor I is not a useful marker of prostate cancer in men with elevated levels of prostate-specific antigen. J Clin Endocrinol Metab 2000; 85:2744-2747.

24. Mantzoros CS, Tzonou A, Signorello LB, Stampfer M, Trichopoulos D, Adami HO. Insulin-like growth factor-1 in relation to prostate cancer and benign prostatic hyperplasia. $\mathrm{Br} \mathrm{J}$ Cancer 1997;76:1115-1118.

25. Soygur T, Kupeli B, Aydos K, Arikan N, Muftuoglu YZ. Effect of obesity on prostatic hyperplasia: its relation to sex steroid levels. Int Urol Nephrol 1996;28:55-59.

26. Daniell HW. Larger prostatic adenomas in obese men with no associated increase in obstructive uropathy. J Urol 1993;149:315317.

27. Meigs JB, Mohr B, Barry MJ, Collins MM, McKinlay JB. Risk factors for clinical benign prostatic hyperplasia in a communitybased population of healthy aging men. J Clin Epidemiol 2001; 54:935-944. 